\title{
A Double Synthetic Index to Evaluate the Acoustics of Churches
}

\author{
Umberto BERARDI \\ Politecnico di Bari, via Orabona 4, Bari, I70125, Italy; e-mail: u.berardi@poliba.it \\ Worcester Polytechnic Institute, 100 Institute Road, Worcester, MA01609-2280, U.S.; e-mail: uberardi@wpi.edu
}

(received April 2, 2012; accepted October 14, 2012)

\begin{abstract}
Several authors have proposed indices to synthesize the acoustics of a space, especially of concert halls. Meanwhile, a few studies have focused on the acoustics of worship spaces. The peculiarities of these last ones have shown distinctive characteristics. The increasing interest for the acoustics of worship spaces justifies the formulation of indices to synthesize the results of acoustic studies in these buildings too. This paper proposes a double synthetic index to evaluate the acoustics of a church. The index is obtained combining the average values of seven parameters generally considered in studies of architectural acoustics. The differences between requirements for music and speech in churches suggest to consider different optimal values of the selected parameters for different kinds of sound. A double synthetic index has been defined to synthesize the acoustical properties related to the music and to the speech separately. The validity of this double index is then assessed, comparing its values with subjective preferences captured through listening tests. The index, which is proposed and validated in this paper, aims to be an instrument to show synthetically the acoustical characteristics of a church to people with low knowledge in acoustics.
\end{abstract}

Keywords: room acoustics, worship acoustics, acoustic quality, synthetic index, listening preference.

\section{Introduction}

The capacity to evaluate the acoustics of a room has always represented a complex task given the high number of characteristics, which have to be considered in the listening perception. In the recent years, an increasing number of parameters have been considered in studies of room acoustics. This has also been determined by the modern technologies, which nowadays allow calculating and measuring many parameters in each point of a room easily and quickly.

Meanwhile, psychoacoustic research has shown that many aspects related to the listening perception are still misunderstood though the large number of parameters which is often considered. Consequently, some recent studies have led to define new parameters related to the subjective perception of room acoustics (Nishi, 1992, OkAno et al., 1998; ANdo, 1998). Most of these parameters have already been introduced in the new standard for measurements of room acoustics (ISO 3382-1, 2009). A wide number of parameters are hence currently considered to describe the acoustics of a room.

In this scenario, an increasing attention towards ways to synthesize the information about the acousti- cal characteristics of a room has recently emerged. Several authors have proposed synthetic indices to assess the acoustics of a space. As most of the studies about architectural acoustics have focused on spaces for performances, single indices have been developed mainly for concert halls (CREMER, Muller, 1982; ANdo, 1998; BeraneK, 1996; 2004). However, in this paper, the attention is focused on worship spaces. In fact, an increasing number of studies have been focused on the acoustics of churches, whose peculiarities are different from those of concert halls and theatres (BERARDI et al., 2009a). Large surveys have contributed to create a consistent body of knowledge about the acoustics of churches in Portugal (CARvalho, 1994), Spain (Sendra et al., 1999), Poland (Kosala, Engel, 2005), Italy (Cirillo, Martellotta, 2006), and Japan (SoETA et al., 2012). Meanwhile recent research has extensively investigated relations between church shapes and acoustics (BERARDI, 2011; 2013).

While a larger attention is currently assigned to churches, subjective evaluations in these buildings are still rare. In fact, the literature about the optimal acoustical conditions in churches is limited. According to psychoacoustic surveys, the acoustics of large gothic churches and of small protestant parishes can 
be assessed favourable by listeners despite their great differences (CARvalho et al., 1997; Martellotta, 2008). This shows that desirable acoustical conditions of churches can be largely different also considering the kinds of sounds in a church. Music, from Gregorian to Masses, and speeches, from prayers to sermons, are generally performed in churches almost at the same time.

The lack of a specific "acoustic" destination of a church contributes to the difficulty of defining optimal acoustical conditions.

This paper hopes to review existing literature about the optimal conditions in churches and to propose a synthetic way to evaluate the acoustics of a church. The scope is particularly ambitious because the index can offer a way to show acoustical properties of a church to people with low knowledge of acoustics, such as priests and faithful. However, it is important to stress that the definition of a single index does not aim to establish an instrument to classify churches, but it only hopes to be useful to summarize the acoustics of churches.

This paper is structured in the following way: Sec. 2 reviews single indices for the evaluation of acoustics in concert halls and in churches, Sec. 3 develops a new index to evaluate the acoustics of churches and Sec. 4 validates this index comparing its values with the preferences obtained through listening tests. Conclusions are reported in the last section together with suggestions for further studies.

\section{Literature review of single indices for room acoustics}

\subsection{Indices for Concert Halls}

The synthesis of room acoustical parameters in a single index requires to select independent parameters and to combine them considering their relative importance. A good starting point for this scope is the understanding of the parameters, which influence the listeners' perception. A factor analysis has often been used to decompose listeners' judgments indicating the most influencing aspects of the perception. Using this method, NisHi (1992) found that few parameters are sufficient to represent human subjective preference. These factors were related to the reverberance of the room, the clarity, the ratio between high and mean/low frequencies, the lateral energy component, and the ratio between front and back sound energies.

Hence, several parameters have been defined for measurements of room acoustics to properly consider previous factors. Nowadays, the most validated parameters are reported in the international standard ISO 3382-1 (2009). However, the high number of these parameters has recently raised an interest towards syn- thetic indices to evaluate the acoustics of a room. The most diffused of these indices have been proposed by Ando (1998) and BerAnEK (1996; 2004), and were specifically defined for concert halls.

Ando (1998) based its index on six acoustic parameters combined together according to weights defined through psychoacoustic evaluations. The parameters were selected to describe different characteristics of the room after having verified that the parameters were orthogonal (i.e. independent). These parameters were the early decay time (EDT), the sound strength $(\mathrm{G})$, the inter-aural cross-coefficient (IACC), the initial time delay gap (ITDG), the bass ratio (BR) and the scattering diffuseness (SDI). Ando proposed to compare the value of each parameter (par) with the optimal one for that parameter (par optimal) in order to obtain the partial index $\left(x_{i}\right)$, and then to recompose the partial indices into the final index $(S)$, according to coefficients $\left(a_{i}\right)$ that weight the psychological influence of each parameter. The formulas proposed by Ando (1998) for the single index are:

$$
x_{i}=\log \left(\text { par } / \text { par }_{\text {optimal }}\right) \rightarrow S=\sum a_{i}\left|x_{i}\right|^{3 / 2} .
$$

The parameters selected by Ando are also used in the index proposed by BERANEK (2004). The main difference of this last index is in the way to compare the average values with the corresponding optimal values. In fact, BERANEK (2004) reports some figures, which have to be considered to calculate the partial indices for each parameter.

Having determined the partial indices from comparisons between the average values and desired values, it is necessary to recompose the partial indices into a single index through weighted averages. The weights $\left(a_{i}\right)$ given by Ando and Beranek to recompose the different partial indices are 0.25 for EDT and IACC, 0.15 for G and SDI, 0.10 for ITDG and BR.

Finally, the method proposed by Beranek has shown a good capacity to represent the acoustics of concert halls since a good agreement was shown between the values of the synthetic index and the subjective preferences (BERANEK, 2004).

\subsection{Indices for worship buildings}

Worship acoustics is receiving more and more attention, although only a few studies have focused on the optimal preferred conditions in churches. Moreover, the listening tests to measure subjective preferences are rare (CARVAlHo et al., 1997; MARTEllotta, 2008).

As the amount of parameters that are collected studying the acoustics of a worship building is wide, a recent theme of research is represented by the formulation of synthetic indices in churches.

ENGEL and KosAla (2007) have proposed a synthetic index to combine the acoustical parameters in a 
church, the index called Global index of acoustic quality. They combined partial indices obtained through comparisons of the value of the acoustical parameters in the church and their optimal values. The authors considered a large number of partial indices and suggested an open methodology which could be used to consider more parameters than those indicated by the authors: the reverberation index (calculated from the reverberation time $\mathrm{T}$ ), the music sound quality index $\left(T_{S}, \mathrm{BR}, \mathrm{C}_{80}\right)$, the external disturbance index (calculated from the Sound Pressure Level), the intelligibility of speech index $\left(\mathrm{AL}_{\mathrm{CONS}}\right.$, RASTI and $\left.\mathrm{C}_{50}\right)$ and the uniformity of the loudness index (from the variations of G). This index has recently been used to synthesize the acoustics of a new Portuguese church (CARVAlHo, SILVA, 2010).

All the parameters are connected in one index called Global index of acoustics quality, which is formulated in a way similar to the classical approaches for concert halls, i.e. according to the following expression:

$$
W_{J A S}=\sum_{i=1}^{n} W_{i} \eta_{i} / \sum_{i=1}^{n} \eta_{i}
$$

where $W_{i}$ is the partial index and $\eta_{i}$ is the corresponding $i$-weight.

An important characteristic, which emerges in this index, is the inclusion of parameters related both to the musical perception and speech intelligibility. This choice agrees to the different kinds of sound, which are typically present in churches.

More recently, Kosala (2011) has revalued the importance of the independence between the parameters and, consequently, he has limited the number of considered parameters. Kosala (2011) has proposed a synthetic global index, which is obtained combining only three partial indices through the Singular Value Decomposition method. In this method, the problem of redundant information related to the relative weight among the partial indices is solved using a computed pseudoinverse matrix. Through this method Kosala (2011) has reported an analytically elegant, although complex, way to combine three partial indices. These partial indices are the reverberation index, which is a function of the reverberation time (RT), the music sound index, the clarity $\left(\mathrm{C}_{80}\right)$ and the speech intelligibility index i.e. function of the RASTI.

As in the first formulation by ENGEL and KosALA (2007) also in the new version formulated by KosALA (2011), there is the contemporary presence of parameters related to assess the perception of music and speech. In this way, the index of Kosala shows unsuited to mark differences in the acoustics of a church related to the music or to the speech. In fact, a same value of $W_{J A S}$ can be obtained by churches with acoustical conditions optimal for music and negative for speech, or the reverse.

\section{A new double synthetic index for churches}

A new index to synthesize the acoustics of churches is proposed in this section. This index follows the necessity to overcome the limit of the index of Kosala (2011) which has the disadvantage to combine together parameters related to the music and the speech and doing this is unsuited to discern the peculiarities of church acoustics.

For the scope of this section, it is necessary to select the acoustical parameters, which lead to the partial indices, to select their optimal values, and to establish the way to compare the values of each parameter with the optimal one.

The selection of the parameters to be considered and of their optimal values is complicated by the different requirements of preferred listening conditions for music and speech. This suggested to avoid the formulation of a single index, as the same acoustical condition can result favourable for music and negative for speech, or reversely. In fact, a unique index difficulty represents often contrasting aspects of the acoustics of a church related to music and to speech and can lead to misunderstand the meaning of its value. In fact, the main limit of the existing indices is represented by their inability to represent the different and specific acoustic properties of churches. Consequently, a compromise between synthesis and communicability of the index has suggested to adopt different optimal conditions for the acoustical parameters that have been selected. In this way, a double index has been formulated which can easily be adapted to the musical perception and speech intelligibility.

Five different acoustical peculiarities were considered: reverberation, sound quality, spaciousness, sound strength and clarity. In order to describe these peculiarities, seven parameters were considered according to the result of psychoacoustic studies in churches (CARvalho et al., 1997; Martellotta, 2008).

The reverberation of the church was represented by the value of the early decay time (EDT). In fact, according to the results of a recent study and given the frequent presence of the late reflections, the EDT has a better correlation with subjective judgments than the $\mathrm{T}$ in churches (MARTEllotTa, 2008). The sound quality was expressed through two parameters, BR and $T_{S}$. In this way, both the differences among bass and high frequencies and the balance between the first and last reflections were considered. The spaciousness of the room was expressed through two parameters, LF and IACC. Finally G represented the sound strength, while the clarity was represented by $\mathrm{C}_{50}$.

Before defining the weights, it was necessary to verify the independence between the parameters and their orthogonality. This assessment was done considering the correlation between the average values that the previous parameters assumed in 37 Italian churches 
Table 1. JND values, the $a$ weight for each of the seven parameters selected and their optimal values for the music and speech indices.

\begin{tabular}{|c|c|c|c|c|c|c|c|}
\hline & $\begin{array}{c}\mathrm{EDT} \\
(500-1 \mathrm{k})\end{array}$ & $\mathrm{BR}$ & $\begin{array}{c}T_{S} \\
(500-1 \mathrm{k})\end{array}$ & $\begin{array}{c}\mathrm{LF} \\
(125-1 \mathrm{k})\end{array}$ & IACC & $\begin{array}{c}\mathrm{G} \\
(500-1 \mathrm{k})\end{array}$ & $\begin{array}{c}\mathrm{C}_{50} \\
(500-1 \mathrm{k})\end{array}$ \\
\hline $\mathrm{JND}_{i}$ & $5 \%$ & 0.1 & $10 \mathrm{~ms}$ & $5 \%$ & $7.5 \%$ & $1 \mathrm{~dB}$ & $1 \mathrm{~dB}$ \\
\hline$a_{i}$ & 0.25 & 0.05 & 0.15 & 0.15 & 0.10 & 0.15 & 0.15 \\
\hline Optimal value in music index & $2.1-4.2 \mathrm{~s}$ & 1.10 & $<300 \mathrm{~ms}$ & $>25 \%$ & $35 \%$ & $>3 \mathrm{~dB}$ & $>-6 \mathrm{~dB}$ \\
\hline Optimal value in speech index & $0.8-1.0 \mathrm{~s}$ & 1.05 & $<150 \mathrm{~ms}$ & $>20 \%$ & $35 \%$ & $>0 \mathrm{~dB}$ & $>0 \mathrm{~dB}$ \\
\hline
\end{tabular}

(BERARDi et al., 2009b). The acoustical parameters in these churches had been measured during a project which allowed to survey the most important churches around Italy that belonged to different ages and of different dimensions (Cirillo, MartellotTA, 2006). The values assumed by the above parameters in different churches were averaged for each church and the statistical correlation $R^{2}$ were determined. The correlations always revealed very low values. In particular, the highest correlation was obtained between the values of $\mathrm{LF}$ and $\operatorname{IACC}\left(R^{2}=0.609\right), T_{S}$ and $\mathrm{C}_{50}$ $\left(R^{2}=0.593\right)$ and $T_{S}$ and $\operatorname{EDT}\left(R^{2}=0.446\right)$. As evident the coefficients of correlation were always low showing that the orthogonality of the selected parameters was respected.

The partial indices were calculated by comparing selected parameters with the optimal values. They assumed different values in the two indices according to the different optimum conditions for music and speech. For each parameter, the value of the partial index was measured with a linear comparison between the measured values and the optimal ones. Having recognized that the linear correlation would not consider the listening capacity to recognize differences of the parameters, it was decided to take into account the just noticeable difference (JND) of each parameter. The values of JND were taken from the ISO 3382-1 (2009) and literature studies (MARTELlotTA, 2010). Finally, an optimal interval was defined for each parameter.

Table 1 reports the JND value and the weight for each parameter together with the optimal values in the music and speech indices. The partial weights given to any parameter $\left(a_{i}\right)$ were similar to those defined by BERANEK and ANDO. Some differences were related to the peculiarities of the churches and the selection of a different set of parameters was necessary.

The weight given to EDT (0.25) is the highest, among the others according to the role that reverberation has for the acoustics of a church.

The sound energy coming from a lateral direction plays an important role in the perception of room acoustics: in the single indices proposed for concert halls, it received a weight of $25 \%$ and was assessed through a single parameter given the correlation of LF and IACC in concert halls (OKANO et al., 1998). Reversely, in churches, the LF and IACC have shown to be independent of each other and were considered both. Also the lateral energy has a total weight of 0.25 , divided between 0.15 assigned to LF and 0.10 to IACC.

All the other parameters received a weight of 0.15 , except the BR which, given the lack of literature about its best value, was awarded a weight of 0.05 only.

Having established the mean values inside the church $\left(\bar{P}_{i}\right)$ and the optimal value for each parameter $\left(P_{i_{-} o p t}\right)$, the formulas to calculate the partial indices $\left(P_{i}\right)$ and from these the single index $(P)$ are:

$$
P_{i}=1-\left|\frac{\left(P_{i_{-} o p t} \pm \mathrm{JND}_{i}\right)-\bar{P}_{i}}{P_{i_{-} o p t}}\right| \rightarrow P=\sum_{i=1}^{7} P_{i} a_{i} .
$$

The values of $P_{i}$ in (3) may vary from 1 to 0 in case of values lying within the optimal values interval. The same range from 1 to 0 is valid also for the single in$\operatorname{dex} P$. In the next subsections the selection of the optimal values for the music and the speech indices in churches will be discussed.

\subsection{The single music index}

The optimal values of each acoustical parameter were chosen according to the findings in literature about worship acoustics as explained below:

- the optimal values for EDT in churches were between 2.1 and $4.2 \mathrm{sec}$. These values are much higher than those commonly accepted in concert halls or theatres. Some considerations justify this assumption: BERANEK (1996) gives an optimal value in concert halls with symphonic music laying between 2.2 and $2.6 \mathrm{sec}$, whereas studies in churches show optimal values much higher than those in concert halls. Subjective tests have indicated the listeners' preference in Italian Catholic churches between 2.1 and $4.2 \mathrm{sec}$ (Martellotta, 2009). Hence, this interval has been selected as the optimal one. However, other intervals can be considered optimal for different kinds of churches (Orthodox or Protestant churches), where architectural characteristics and acoustical requirements differ significantly;

- Ando and Beranek's studies were considered for the optimal value of BR. ANDO (1998) suggests an interval between 1.1 and 1.25 , when the reverberation 
times are $2.2 \mathrm{sec}$ and lower values for higher reverberations. Reversely, BERANEK (1996) suggests an interval between 0.9 and 1.2 independently from the reverberation of the room. Averaging these two intervals, and considering that high reverberation times are common in churches, the optimal value for BR was assumed to be equal to 1.1;

- the optimal value for $T_{S}$ was assumed to be equal to $300 \mathrm{~ms}$ according to the value found in churches in the study of MARTELLOTTA (2008);

- considering the importance that the lateral energy has for the music perception, the optimal value for LF was assumed to exceed $25 \%$. Moreover, using the suggestion of BERANEK (2004), the optimal value of IACC was assumed to exceed $35 \%$;

- considering that the optimal sound strength in great rooms (such as churches) is generally high, and following the suggestion of BERANEK (2004), the optimal value of $\mathrm{G}$ for the music index was assumed is greater than $3 \mathrm{~dB}$;

- the optimal value for $\mathrm{C}_{50}$ was chosen according to the indication of MARshalL (1994) and considering an organist repertory. This organ music is common in Catholic churches; however, it may not suit to buildings of other religions. The values of $\mathrm{C}_{50}$ above $-6 \mathrm{~dB}$ were considered optimal for the clarity. The previous value, which may seem low for architectural acoustics, is common in many churches (Kosala, Engel, 2005; Cirillo, Martellotta, 2006) and is partially related to the high reverberation and late reflections in churches (BERARDI et al., 2009a).

The optimal values and the corresponding weights for the music index are reported in Table 1, whereas Fig. 1 shows the functions, which were used to compare the values of each parameter with the optimal ones in the music index.

\subsection{The single speech index}

The synthetic speech index was similar to the music index since it adopted the same parameters and weights. The only difference was represented by the optimal values of the different parameters.

BERANEK (2004) showed the relation of the speech intelligibility with few parameters: $\mathrm{G}, \mathrm{C}_{50}, \mathrm{EDT}, \mathrm{LF}$ and IACC. They are all considered in the proposed single speech index. BR represents the only difference of the speech index, which is particularly important in churches for their frequency selectivity due to their large volumes. The optimal values for each parameter in the speech index were:

- for the EDT, the interval between 0.8 and 1.0 sec was considered optimal. These values lower than those admitted for the music-index are related to the preference of less reverberation for optimal speech listening;

- the optimal BR was assumed to be 1.05 since more equilibrium among frequencies is preferable for speech listening;

- the optimal LF was assumed to be above $20 \%$ since the speech listening preference results in lower values than for music. Moreover, using the suggestion of BERANEK (2004), it was assumed that the optimal value exceeds $35 \%$;

- the optimal $T_{S}$ was assumed to be $150 \mathrm{~ms}$, equal to the half of the previous one;

- the optimal $\mathrm{G}$ was $0 \mathrm{~dB}$ according to the value for theatres reported by BERANEK (1996);

- the value of clarity $\mathrm{C}_{50}$ was assumed as optimal for the intelligibility of speech above $0 \mathrm{~dB}$.

Figure 2 shows the functions, which were used to compare the value of each parameter with the optimal ones in the speech index. As evident, the optimal value considers the JND for the different parameters with a consequent increase of the interval which is considered preferable and which corresponds a partial index of 1 .

\section{MUSIC INDEX}
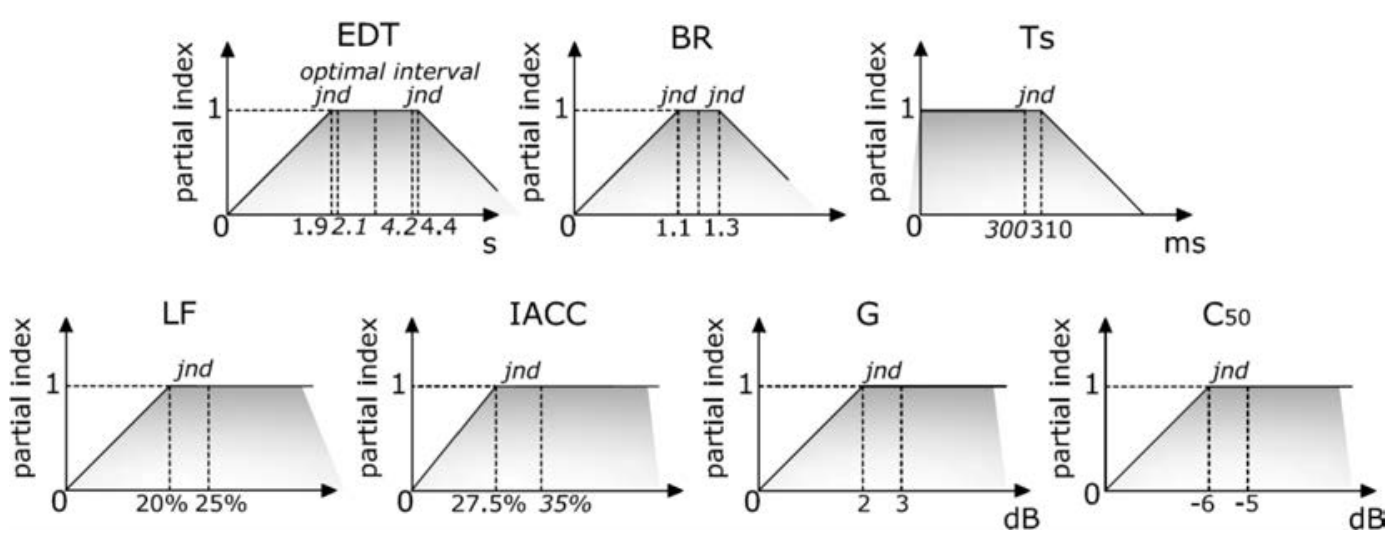

Fig. 1. Graphic representation of values of the seven partial indices for the single music index. 


\section{SPEECH INDEX}
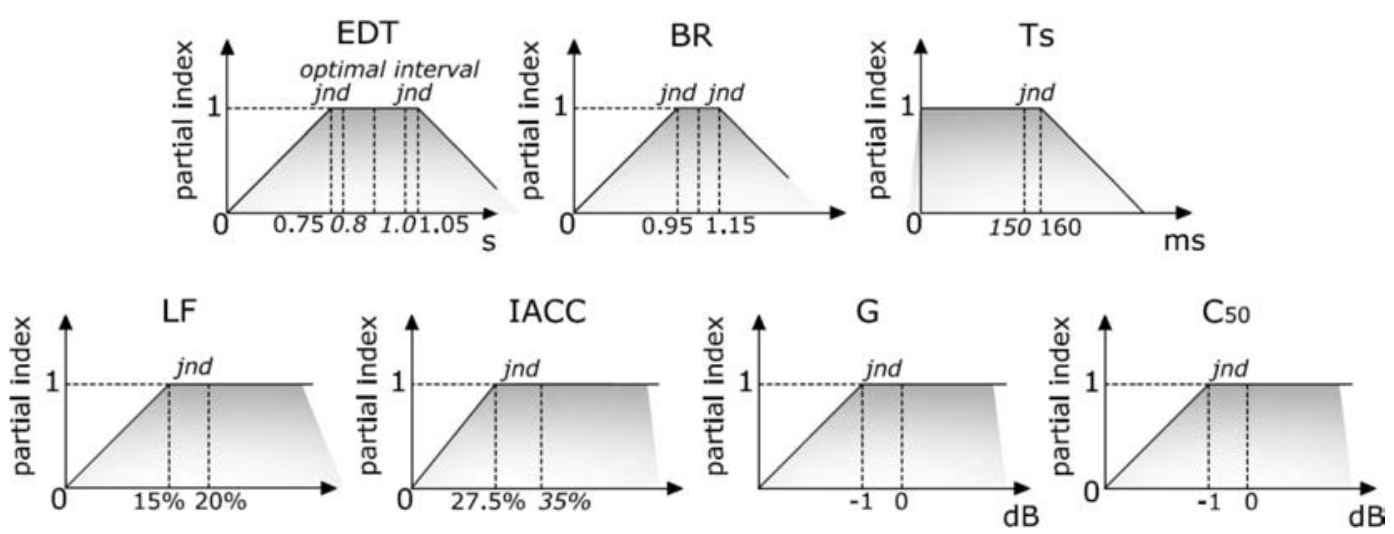

Fig. 2. Graphic representation of values of the seven partial indices for the single speech index.

\section{Validation of the double synthetic index in some churches}

In this section, the validation of the music and speech indices is done by comparing their values with listener's preferences in some churches. For this scope, three churches were considered. They were geographically distributed in Italy and were: the Cathedral of San Cataldo in Taranto (church A), the church of Santa Maria della Consolazione in Todi ( church B) and the church of Santi Martina e Luca in Rome (church C).

In each church, an acoustical survey had been conducted and the parameters proposed by the ISO 3382-1 have been calculated (Cirillo, Martellotta, 2006). The surveys in these rooms were conducted in unoccupied conditions. The synthetic indices were hence calculated after having averaged the value of each parameter in several positions of measurements.
Table 2 reports the average values of the seven parameters in the three churches surveyed by CIRILLO and Martellotta (2006).

According to the formulation of the indices, the maximum value that could be obtained in a church is 1 , while a 0 value was assumed if the parameters have values particularly far from the optimal ones.

Table 3 reports the average value of the seven partial indices, and the result of the music index in the three churches. The music index assumed a high value (near to 1 and hence, to the optimal conditions) in church A. A particularly high value was shown by church C, whereas church B revealed a low music index due to the too long reverberation and high EDT.

Calculating the speech index, the partial indices assumed negative values according to the large differences between the measured values and the optimal ones (Table 4). A good value of the speech index

Table 2. Average values of seven parameters in three Italian churches (Cirillo, Martellotta, 2006).

\begin{tabular}{|c|c|c|c|c|c|c|c|c|}
\hline Church & $\begin{array}{c}\text { Volume } \\
{\left[\mathrm{m}^{3}\right]}\end{array}$ & $\begin{array}{c}\text { EDT } \\
{[\mathrm{s}]}\end{array}$ & $\begin{array}{c}\text { BR } \\
{[-]}\end{array}$ & $\begin{array}{c}T_{S} \\
\mathrm{~ms}\end{array}$ & $\begin{array}{c}\mathrm{LF} \\
{[\%]}\end{array}$ & $\begin{array}{c}\text { IACC } \\
{[\%]}\end{array}$ & $\begin{array}{c}\mathrm{G} \\
{[\mathrm{dB}]}\end{array}$ & $\begin{array}{c}\mathrm{C}_{50} \\
{[\mathrm{~dB}]}\end{array}$ \\
\hline Cathedral of San Cataldo - Taranto (A) & 9000 & 2.1 & 1.10 & 150 & $30.0 \%$ & $73.9 \%$ & 7.2 & -4.2 \\
\hline Santa Maria della Consolazione - Todi (B) & 19000 & 8.8 & 1.26 & 656 & $17.5 \%$ & $48.2 \%$ & 10.9 & -11.7 \\
\hline Santi Martina e Luca - Rome (C) & 10000 & 3.3 & 1.13 & 234 & $21.1 \%$ & $57.0 \%$ & 9.8 & -5.7 \\
\hline
\end{tabular}

Table 3. Average values of seven partial indices in three Italian churches, and result of the music index.

\begin{tabular}{|c|c|c|c|c|c|c|c|c|}
\hline Church & EDT & BR & $T_{S}$ & LF & IACC & G & C $_{50}$ & Music index \\
\hline Church A & 0.78 & 1.00 & 1.00 & 0.86 & $0(-0.11)$ & 0.72 & 0.58 & 0.71 \\
\hline Church B & $0(-3.15)$ & 0.85 & $0(-2.37)$ & 0.55 & 0.52 & 0.91 & $0(-0.17)$ & 0.31 \\
\hline Church C & 0.07 & 0.97 & 0.44 & 0.60 & 0.37 & 0.98 & 0.43 & 0.47 \\
\hline
\end{tabular}

Table 4. Average values of seven partial indices in three Italian churches and result of the speech index.

\begin{tabular}{|c|c|c|c|c|c|c|c|c|}
\hline Church & EDT & BR & $T_{S}$ & LF & IACC & G & C50 & Speech index \\
\hline Church A & 0.67 & 1.00 & 0.50 & 0.86 & $0(-0.11)$ & 0.39 & 0.69 & 0.56 \\
\hline Church B & $0(-0.82)$ & 0.85 & $0(-0.19)$ & 0.55 & 0.52 & $0(-0.42)$ & 0.06 & 0.19 \\
\hline Church C & 0.94 & 0.97 & 0.78 & 0.60 & 0.37 & $0(-0.18)$ & 0.95 & 0.61 \\
\hline
\end{tabular}


was obtained in church $\mathrm{C}$, whereas an average value was obtained in church A. Finally, the large volume of church B, which had determined a very long reverberation (EDT value of $8.8 \mathrm{~s}$ ), was responsible for the low value of the speech index.

Tables 3 and 4 report the value of 0 for partial indices, which significantly deviate from the preferred interval. However, the values in parenthesis represent the value that would be obtained by the analytical formula (3) if negative indices were accepted.

The values of the music and speech indices in the three churches had resulted aligned with the subjective preferences, which had been captured for these three churches by MARTELLOTTA (personal communication, also in (2008)). In fact, church A had revealed to be particularly suitable for music listening, whereas good capacities of speech listening had been measured in church C. Finally, church B had shown to be particularly problematic both for the music and speech listening.

\section{Conclusions}

Classical methods to determine a synthetic index have been proposed mainly for concert halls. The good correlation between these methods and the subjective judgments has suggested to extend single indices also to churches.

The methodology, which has been proposed in this paper tries to summarize the acoustics of churches through a comparison of seven parameters with the optimal values. In this way, the synthetic index aims to be a way to formulate a synthetic judgment by the values of the many objective parameters that are commonly adopted in room acoustics.

The optimal values were based on studies about subjective preference. The application to churches has suggested the formulation of two different indices in order to separate speech intelligibility and music quality. The double synthetic index has shown a good adherence with subjective preferences and promises to represent a good compromise between synthesis and communicability of the acoustic of a church. In fact, the first applications of the double synthetic index in few Italian churches have revealed its computing speed and robustness to represent listeners' preference.

Future studies are now necessary to test the methodology adopted in this paper and to apply the synthetic index to other churches. The index is hoped to be useful as an instrument to show and synthesise acoustical properties of a church to people with low knowledge in acoustics, but further research about optimal acoustics in churches is necessary.

\section{Acknowledgments}

The author wishes to thank prof. Ettore Cirillo and Francesco Martellotta for having allowed the use of data about the surveys in Italian churches and for their suggestions in an early version of this paper which was presented at the AIA congress in 2009. Finally, the author wants to express his gratitudine for Prof. Cirillo, who has been in many ways much more than a Professor.

Part of this work was presented at Tecniacústica2011 (26-28 Oct, Cáceres, Spain).

\section{References}

1. ANdo Y. (1998), Architectural acoustics: Blending Sound Sources, Sound Fields, and Listeners, Springer, New York.

2. BerAneK L.L. (1996), Concert and Opera Halls - How They Sound, Woodbury - Acoustical Society of America.

3. Beranek L.L. (2004), Concert and Opera Halls - Music, Acoustics, and architecture, Springer.

4. Berardi U. (2011), Predicción de las variaciones espaciales en la acústica de diferentes tipologías de Iglesias, Revista de Acústica, 42, 3-4, 8-16.

5. Berardi U. (2013), Simulation of acoustical parameters in rectangular churches, Journal of Building Performance Simulation, in press.

6. Berardi U., Cirillo E., Martellotta F. (2009a), A comparative analysis of energy models in churches, Journal of the Acoustical Society of America, 126, 4, 1838-1849.

7. Berardi U., Cirillo E., Martellotta F. (2009b), Una metodologia per valutare l'acustica delle chiese, Proc. AIA 2009, Turin (I), 10-12 June 2009, ISBN 97888-88942-23-8.

8. Carvalho A.P.O., Silva P. (2010), Sound, noise and speech at the 9000-seat Holy Trinity, Archives of Acoustics, 35, 2, 145-156.

9. Carvalho A.P.O. (1994), Influence of Architectural Features and Styles on Various Acoustical Measures in Churches, Ph.D. Dissertation, Univ. Florida.

10. Carvalho A.P.O., Morgado A.E.J., Henrique L. (1997), Relationship between subjective and objective acoustical measures in churches, Building Acoustics, 4, $1,1-20$.

11. Cirillo E., Martellotta F. (2006), Worship, acoustics and architecture, Multi-Science Publishing, Essex, UK.

12. Cremer L., Muller H.A. (1982), Principles and Applications of Room Acoustics, Applied Science, London.

13. Engel Z., KosaŁA K. (2007), Index method of the acoustic quality assessment of sacral buildings, Archives of Acoustics, 32, 3, 3-22.

14. ISO 3382-1 (2009), Acoustics - Measurement of room acoustic parameters - Part 1: Performance spaces, International Standard Organisation, Ginevra. 
15. Kosaza K. (2011), A Single Number Index to Assess Selected Acoustic Parameters in Churches with Redundant Information, Archives of Acoustics, 36, 3, 545560 .

16. Kosala K., Engel Z. (2005), Acoustic properties of the selected churches in Poland, Mechanics, 24, 3, 173181.

17. Marshall L.G. (1994), An acoustics measurement program for evaluating auditoriums based on the early/late sound energy ratio, Journal of the Acoustical Society of America, 96, 4, 2251-2261.

18. Martellotta F. (2008), Subjective study of preferred listening conditions in Italian Catholic churches, Journal of Sound and Vibration, 317, (1-2), 378-399.

19. Martellotta F. (2010), The just noticeable difference of center time and clarity index in large reverberant space, Journal of the Acoustical Society of America, $128,2,654-63$.
20. Nishi T. (1992), Relation between Objective Criteria and Subjective Factors in a Sound Field Determined by Multivariate Analyses, Acta Acustica united with Acustica, 76, 4, 153-162.

21. Okano T., Beranek L.L., Hidaka T. (1998), Relations among interaural cross-correlation coefficient, lateral fraction, and apparent source width in concert halls, Journal of the Acoustical Society of America, 104, 1, 255-265.

22. Sendra J.J., Zamarreño T., Navarro J. (1999), Acoustics in churches, [in:] Computational Acoustics in Architecture, J.J. SEndRA [Ed.], Computational Mechanics Publications, Southampton, 133-177.

23. Soeta Y., Ito K., Shimokura R., Sato S., OHSAWA T., ANDO Y. (2012), Effects of sound source location and direction on acoustic parameters in Japanese churches, Journal of the Acoustical Society of America, 131, 2, 1206-20. 